\title{
Yoga Therapy for Treatment of Menstrual Disorders without Obvious Causes
}

\author{
S Chhabra* \\ Obstetrics Gynecology, Mahatma Gandhi Institute of Medical Sciences, India
}

Submission: March 14, 2021; Published: March 20, 2021

*Corresponding author: S Chhabra, Emeritus Professor, Obstetrics Gynecology Mahatma Gandhi Institute of Medical Sciences, Sevagram, Officer on Special Duty, Dr. Sushila Nayar Hospital, Utavali, Melghat, Amravati, Chief Executive Officer, Aakanksha Shishu Gruha, Kasturba Health Society, Sevagram, Wardha, Maharashtra, India

\begin{abstract}
Introduction: Yoga is believed to help women of all ages lead healthier lives, by immediate remedy through relaxation, and deeper action through body mind regulation. It is believed to inspire system that influences one's notions about wellness in life, even in presence of disorders. Menstrual abnormalities are one of most common disorders, women suffer. It may be less or more vaginal bleeding, for short or long duration, less or more interval between two menstrual phases, or continuous bleeding. Sometimes cause is obvious, can be treated. However, if it is not obvious, it may have linkage to notions, not easy to treat.

Objective: To know about status of practice of Yoga for treatment of menstrual disorders in women who do not have obvious disorders.

Material Methods: Studies, reviews in relation to effects of Yoga on menstrual disorders were searched. There was no inclusion, exclusion criteria of studies, reviews. Whatever could be accessed including recorded opinions were looked into.

Results: Yoga is believed to be safe, cost effective therapeutic modality, for good health, wellbeing by regulating body weight, improving biochemical functions, obesity, and metabolic syndrome. Global Multidisciplinary group of researchers, who conducted large clinical trials to examine benefits of Yoga found positive effects of Yoga on Oligomenorrhea, infrequent menstruation, menorrhogia compared to exercise or no activity, in addition to taking an omega-3 supplement or placebo. Yoga might help by improving immune function of body, flexibility, endurance with added psychological benefits, directly and/or indirectly affecting menstrual disorders. However, after reviewing many studies about evidence of effects of Yoga on menstrual disorders, researchers concluded that more research with consistency in methods, measures, quality of studies was warranted.
\end{abstract}

Conclusion: More research is needed about use effectiveness of Yoga practice to treat menstrual disorders.

Keywords: Menstrual disorders; No obvious cause; Yoga practice; Effects

\section{Introduction}

Menstrual abnormalities are one of the most common disorders encountered by women during reproductive life. Abnormal bleeding could occur beyond menopause too. Menstrual problems may be of less or more bleeding, during menstruation, for a short or long duration, with less or more interval between two menstrual phases, bleeding during interval or even continuous bleeding. In some women there are obvious disorders which are responsible for menstrual abnormalities but in others there is no cause. Such cases are usually given some or other hormones. However, hormones used for treating menstrual disorders, are not always effective in relieving symptoms and also, they do have side effects [1]. So search continues for knowing alternative therapies for menstrual disorders, specially those categorized as dysfunctional uterine haemorrhage, meaning there is no obvious pelvic or endocrinal or other such pathologies, but dysfunction in menstruation, difficult to treat.

\section{Objective}

To get information about effects of Yoga practice to treat menstrual dysfunction in women who do not have any obvious disorder.

\section{Material and Methods}

Literature search with available search engines was done to know about studies, and reviews, in relation to Yoga practices and effects on menstrual dysfunction. There were no inclusion or exclusion criteria of studies and reviews. Whatever could be accessed including opinions was looked into and self-observations were added. 


\section{Results}

Yoga is believed to benefit health and wellbeing by regulating body weight and may be by improving body metabolism. So Yoga may be affecting menstrual function too. Menstrual disorders may result from physical disorders, emotional and hormonal disturbances, pathological development of reproductive organs, other organs or even psychological disturbances like depression, fear, or stress. All these are likely to get affected by Yoga practice. Prabhu et al. [2] did a study to know about effects of Yogasanas on menstrual cramps in young and adult women with primary dysmenorrhea and reported that both, Yogasans and Core exercises were useful in reducing menstrual pain. Rani [3] has reported that regular and proper practice of Yoga, Asanas and Pranayamas were beneficial to women who suffered from menstrual disorders, however rest, medicines and relaxation were also necessary. Yoga helped by correcting and balancing the functioning of the endocrine system, toning up the nervous system. It also relaxed the body and mind, which reduced the psychological problems. The Yogic postures helped in preserving the general health and reducing menstrual dysfunctions by improving the vigour and the strength of the body.

It seems that the roots of Yoga might have been in India but the perceived benefits of Yoga have led to its wide acceptability globally. It has been reported that around 15 million Americans practice Yoga [4]. Bullork [5] reported that a multidisciplinary group of researchers conducted large clinical trial to examine the benefits of Yoga compared to exercise or no activity, in addition to taking either an omega-3 supplement or placebo. Study participants included 355 peri- and postmenopausal women aged 40-62 years, who were randomized to one of the three groups, Yoga (107 participants), Exercise (106), and Usual Activity (177). These women were also randomized to receive either $1.8 \mathrm{~g} /$ day of an Omega-3 supplement or an Olive oil placebo capsule. Also those in the Yoga attended weekly, 90-minute classes and were asked to complete a home practice daily for 20 minutes. Yoga practice entailed "doing cooling" pranayama, 11-13 Asans, and yoga nidra guided meditation. However researchers reported that no differences were found for vasomotor symptoms. However, women in the Yoga group reported modest improvement in sleep quality and a reduction in insomnia and depressive symptoms. Results of another pilot study revealed the benefits of Yoga therapy in lowering blood pressure, improving the immune function of the body which directly and indirectly affected menstrual disorders too by improving flexibility, endurance and added psychological benefits [6].

In various studies on the effects of Yoga on Amenorrhea, Oligomenorrhea, Dysmenorrhoea, Premenstrual Syndrome and Premenstrual Dysphonic Disorder enhanced mood, reduced pain, increased wellbeing and a heightened relaxation response were among the improved outcomes reported by women who practised Yoga [7]. Yeun et al. [8] looked into studies and reported that there was objective evidence for Yoga, as a useful complementary and alternative medicine on women with menstrual distress and primary dysmenorrhea. Vaghela et al. [9] reported that when compared the effects of Aerobic exercise and Yoga on premenstrual syndrome, both Aerobic exercise and Yoga practice were effective in treating PMS, however Yoga was more effective in relieving the symptoms of PMS than Aerobic exercise. Aggarwal et al. [10] did a study about effects of Yogasans and Pranayama on pain, severity and quality of life in primary dysmennorhea and reported that Yogasans along with Pranayama technique were more effective than using a single intervention protocol either of Yogasans or Pranayama in primary dysmennorhea.

Not much is known about menstrual irregularities in middle age with or without Polycystic ovarian syndrome (PCOS) and with or without Metabolic syndrome which commonly lead to menstrual abnormalities. Metabolic syndrome is becoming public health problem because it is believed to be a rising issue and probably 20 to 30 percent of women suffer with Metabolic syndrome [11]. 0ates [12] also looked at various studies for effects of Yoga on Amenorrhea, Oligomenorrhea, Dysmenorrhoea, Premenstrual Syndrome and Premenstrual dysphonic disorders reported by women who participated in Yoga practice and reported that menstrual dysfunctions were common and Metabolic disorders too were common. So it becomes essential to know more about the relationship between the two. There is a dramatic change in the way Metabolic syndrome is treated after a growing body of evidence has pointed to Insulin Resistance as an underlying cause of Metabolic Syndrome. Insulin resistance, believed to be a key pathogenic factor in both PCOS and the Metabolic syndrome, may be the thread that links the two conditions [13]. Research on the relationship between Yoga practice and menstrual disorders is warranted, but there must be both consistency in the methods, measures, and quality of studies and a shift towards research on Yoga practice that is replicable outside the clinical trial settings. Goel [14] also reported that various breathing techniques used in Yoga were to improve blood circulation which caused ease of the flow of blood during menstruation. This also relieves pain that is experienced during menstruation. Various positions of Yoga are useful to enhance uninterrupted down flow during menstruation and prevent dysmenorrhea. But they need to be performed with awareness.Yoga is believed to offer both immediate superficial remedy at the body and mind level in the form of relaxation practices and also deeper action by working on, notions about life.

\section{Discussion}

Menstrual disorders may result from physical disorders, emotional and hormonal disturbances, improper development with weak muscles of reproductive organs, imbalance of hormones, weak constitution, pathological and psychological disturbances like depression, fear, stress and mental tension. As Yoga is likely to benefit women with such health problems which have linkages to menstrual disorders, so it could help in relief of 
menstrual dysfunctions. Yoga seems to help by correcting and balancing the functioning of the endocrine system, toning up of the nervous system and also relaxation of the body and mind, thus reducing the psychological problems. Yoga is a correct approach to life, with right diet, exercise and hygiene, quite essential for the normal development and functioning of the reproductive system. The Yogic postures help in preserving the general health and reduce the complaints regarding menstruation by improving the vigour and strength of the body. There is a need for spreading the knowledge about benefits of Yoga practice to large section of the society. This is possible if practice of Yoga is validated through exhaustive research based on standard parameters. Scientific exploration of Yoga in women with interdisciplinary approach is needed. While treating menstrual disorders, the major goal is to treat the underlying cause and when cause is not obvious, it is usually difficult to treat. Hormonal therapies may or may not be effective in relieving the symptoms and they have their side effects too. In some women they are contraindicated too. So research continues to identify the efficacy of alternative therapies for menstrual dysfunction. Yoga seems to be an alternative or primary treatment, for maintaining health and wellbeing by regulating body weight, improving biochemical functions overcoming the obesity related complications as well as Metabolic syndrome which lead to relief from menstrual dysfunction.

So, Yoga is likely to be beneficial in treating Metabolic Syndrome and so menstrual disorders also [15]. More research is needed for identifying the efficacy of Yoga in menstrual dysfunction, to know about Yogasanas with various postures through which the physical revitalization, deep relaxation and mental calmness are achieved. Yoga recognizes the link between breathing and calmness of the mind, which could be beneficial in premenstrual syndrome too and also help relief from other menstrual disorders, like menopauserelated, hot flashes, night sweats, and fatigue negatively which impact the quality of life of millions of women. After looking at evidence of effects of Yoga on menstrual disorders by reviewing many papers Oates [12] also concluded that more research about relationship between Yoga practice and menstrual disorders was warranted. Also, there is need of a deeper understanding of the effects of Yoga on menopausal menstrual effects, especially those without any obvious organic disorders. Yoga is known to play an important role in reducing stress and sympathetic activity, increasing parasympathetic activity, improving one's quality of life, and also by decreasing psychological symptoms. It also has beneficial effects on physical and mental health through down regulation of the hypothalamic- pituitary- adrenal axis and the sympathetic nervous system, which may also be useful for managing primary dysmenorrhea. Yoga asanas help in increasing the flow of vital energy to the reproductive organs and establishes a balance among hormones regulating menstruation. While practicing Yoga it should be kept in mind that the number and the sequences should always be modified according to the capacity and other conditions of the person. One must avoid practicing Yoga by just looking at the television or by reading a book on Yoga therapy. The practice should be learnt from a qualified Yoga therapist. This is cost effective and can be used as a exercise for menstrual well-being and help improve quality of life.

\section{Conclusion}

Available literature reveals that Yoga is helpful in management of menstrual disorders however more well-designed research is needed.

\section{References}

1. Freeman EW (2002) Treatment of depression associated with the menstrual cycle: premenstrual dysphoria, postpartum depression, and the peri menopause. Dialogues Clin Neurosci 4(2): 177-191.

2. Prabhu S, Nagrale S, Shyam A, Sancheti A (2019) Effect of Yogasanas on Menstrual Cramps in Young Adult Females with Primary Dysmenorrhea. Int J Physiother Re 7(4): 3129-3134.

3. Rani k (2011) Six months trial of yoga Nidra in Menstrual Disorder patients: Effect pm somatoform symptoms. Ind Psychiaty J 20(2): 97102.

4. Finkk NS, Urech C, Isabel F (2011) Fetal response to abbreviated relaxation techniques randomized controlled study. Early Hum Dev 87(2): 121-127.

5. Bullock BG (2020) E-RYT 500 is a psychologist, research scientist, educator, author, yoga and mindfulness expert and creator of BREATHE: 7 Skills for Mindful Relationships.

6. Previti G, Pawlby S, Choudhary S, Aguglia E, Pariante CM (2014) Neurodevelopment outcome for offspring of women treated for depression: a systematic review. Arch Womens Ment Health 17(6): 471-483.

7. (2017) Mary Ann Liebert can Yoga Reduce Symptoms of Menstrual Disorder?

8. Yeun YR, HY Woo (2019) The effects of yoga on the menstrual distress and menstrual pain of women with primary dysmenorrhea: a systematic review and meta-analysis. Biomedical Research 30(5): 693-697.

9. Vaghela N, Mishra D, Sheth M (2019) To compare the effects of aerobic exercise and yoga on Premenstrual syndrome. J Educ Health Promot 8: 199.

10. Aggarwal A, Rao T, Palekar T (2020) Effect of Yogasanas and Pranayama on Pain, Severity and Quality of Life in Primary Dysmennorhea. Int J Med Public Health 10(1): 38-42.

11. Brady C, Mousa S S, Mousa S A (2009) Polycystic ovary syndrome and its impact on women's quality of life: More than just an endocrine disorder. Drug Healthc Patient Saf 1: 9-15.

12. Oates J (2017) The Effect of yoga on Menstrual Disorder, J Altern Complement Med 23(6): 407-417.

13. Fayli H T, Arslanian S (2008) Menstrual Health and the Metabolic Syndrome in Adolescents. Ann N Y Acad Sci 1135: 85-94.

14. Goel S (2013) Yoga for Menstrual Disorder, Yoga Doctor.

15. Alexander GK, Innes KE, Selfe TK (2013) "More than I Expected": Perceived Benefits of Yoga Practice among Older Adults at Risk for Cardiovascular Disease. Complement Ther Med 21(1): 14-28. 
(c) (1) This work is licensed under Creative BY DOI: 10.19080/JYP.2021.08.555747
Your next submission with Juniper Publishers will reach you the below assets

- Quality Editorial service

- Swift Peer Review

- Reprints availability

- E-prints Service

- Manuscript Podcast for convenient understanding

- Global attainment for your research

- Manuscript accessibility in different formats ( Pdf, E-pub, Full Text, Audio)

- Unceasing customer service Track the below URL for one-step submission https://juniperpublishers.com/online-submission.php 